\title{
ESTUDOS PRELIMINARES ACERCA DO PROCESSO DE ELABORAÇÃO DA OBRA KOJIKI
}

Luís Fábio M. Rogado Mietto

\section{Introdução e Características Gerais da Obra}

O presente trabalho tem por objetivo a apresentação sumária das principais características da obra Kojiki, assim como a tradução comentada do seu prefácio. A escolha do prefácio da obra para a tradução deve-se a este ser a única fonte disponível de dados sobre o processo, sobre os documentos utilizados e os objetivos de sua compilação.

A obra Kojiki, concluída em 712 d.C. por Ônoassomiyasumaro, no início da era Nara (710-784), sob ordens da Imperatriz Genmei, constitui-se no mais antigo repositário de lendas e mitos do Japão antigo, registrando um período que se estende desde a era dos deuses, até o reinado da Imperatriz Suiko (593-628).

Entretanto, este não foi o primeiro esforço de elaboração de registros históricos no Japão. Têm-se notícias, por exemplo, do registro do Tennôki (Registros dos Imperadores), do Kokki (Registros Nacionais) e do Hongi (Registros Fundamentais), sob iniciativa de Shôtoku Taishi em 620, todos destruídos em 645, após a Reforma de Taika.

A obra Kojiki divide-se basicamente em três partes: a primeira parte registra a criação do universo e do arquipélago japoneses. Seu clímax é alcançado com a seqüência mítica do "descendente dos deuses", na qual a prole dos deuses celestes é enviada para governar o Japão. Termina com a posse do lendário Imperador Jinmu, considerado o primeiro imperador do Japão e descendente da deusa do sol Amaterasu. A segunda parte cobre desde o reinado do Impe- 
rador Jinmu até o reinado do Imperador Ôjin, em princípios do século V. A terceira parte inicia com o Imperador Nintoku e termina com a Imperatriz Suiko, em princípios do século VII, consistindo-se basicamente em registros de sucessão imperial.

De acordo com o prefácio, durante a metade do século VII o Imperador Tenmu ordenou que o Teiki (registro genealógico da familia imperial) e o Kyâji (coletânea de mitos, lendas e canções) fossem corrigidos devido a seus dados estarem incorretos e por estes se constituírem nas "linhas mestras da organização do país" e nas "diretrizes do poder imperial". O Imperador Tenmu incumbiu um atendente da corte, Hiedano Are, a memorizar o conteúdo do Teiki e do Kyâji. O projeto foi interrompido, como é indicado pela seguinte passagem do prefácio: "Entretanto, o tempo passa e o mundo se transforma, não conseguindo completar o seu trabalho", devido à morte deste imperador em 686, cerca de um ano após ter ordenado a elaboração dos registros. $O$ projeto foi retomado apenas em 711, quando a Imperatriz Genmei determina a continuação deste trabalho por Ônoassomiyasumaro. Em 712, quatro meses após o decreto imperial, a obra é apresentada à corte japonesa.

De acordo com os historiadores, as prováveis fontes utilizadas no processo de compilação, além das indicadas no prefácio da obra, são:

1. o Teiki e o Kyûji;

2. tradições orais transmitidas pelos kataribe, cuja função era a preservação de informações transmitidas oralmente antes do advento da escrita;

3. repertórios dos músicos da corte, que preservaram inúmeras canções e danças japonesas nativas, assim como músicas de origem estrangeira;

4. lendas populares, crenças e mitos, em especial as etimologias folclóricas de nomes de lugares e citações de provérbios;

5. registros de origem estrangeira, pois algumas das seqüências surgidas na obra contêm elementos passíveis de correlação com mitos do sudeste asiático, Coréia ou China;

6. a própria corte em si, visto que a unificação do país tornava necessária a criação de uma mitologia de cunho oficial que legitimasse sua posição.

Com relação aos manuscritos existentes, o mais antigo é conhecido como o Manuscrito do Templo Shinpuku, copiado entre 1371 e 1372 pelo monge Ken'yû. A primeira edição data de 1644 e, entre as edições posteriores, a edição crítica de Tanaka em 1887 é de imenso valor. A tradução do prefácio baseou-se na contida em Kojiki*.

Como anteriormente mencionado, a análise do processo de elaboração do Kojiki deve ter necessariamente como ponto de partida o prefácio. Mas, para uma compreensão global da obra, a seguir apresentamos breves considerações acerca do panorama histórico do período.

- In: Nihon Koten Bungaku Zenshu (Obras Completas da Literatura Japonesa Clássica). 


\section{Panorama Histórico do Periodo}

O término do Kojiki deu-se na era Nara, época em que se completa o processo de unificação política e de estratificação social do Japão, ambos em curso desde o século III, com a consolidação da hegemonia da família imperial japonesa.

Deve-se notar que, do século I ao II, o Japão encontrava-se dividido em pequenos estados de coligações tribais, ou uji, unidades patriarcais nas quais seus memòros tinham um certo grau de parentesco, comportando também elementos agregados sem relações de sangue com o grupo, numa estrutura basicamente tribal e gozando de certa autonomia. $O$ líder destes grupos, ou uji no kami, era escolhido entre os seus membros mais idosos e, após sua morte, passava a ser visto como divindade, a quem se prestava culto.

Os elementos sem relação de parentesco agregados a cada uji eram os be e os tomo, grupos encarregados de atividades importantes para a comunidade como tecelagem, fabrico de instrumentos, utensílios, armas, prestação de serviços militares ou de funções religiosas. Embora os membros destes grupos não tivessem um ancestral comum, sua posição e pertinência ao grupo era hereditária, não podendo abandonar a comunidade e estando subordinados ao controle de um líder, cuja posição também era hereditária. Com o tempo, eles se fundem ao uji ao qual estavam agregados, clamando seu nome e ancestrais. Além disso, a própria organização destas unidades também sofre transformações - alguns uji ganham supremacia sobre seus vizinhos mais fracos formando, deste modo, agrupamentos de uji. A origem do núcleo constituinte do futuro estado japonês estava num desses agrupamentos.

O uji que origina a família imperial japonesa estende seu poder gradualmente num processo passível de divisão em três fases consecutivas:

1. através de Shotoku Taishi, em finais do século VI;

2. através da burocratização da máquina governamental em fins do século VII, como resultado da Reforma de Taika de 645;

3. através da completa sistematização da autoridade centralizada, surgida com a introdução do Código Taihô Ritsuryô em 701.

Na realidade o Estado Ritsuryô foi um prolongamento do sistema conhecido como uji-kabane, modo de organização da elite política precedendo a Reforma de Taika. Neste sistema, alguns uji recebiam uma titulação adicional o kabane, permitindo que este tivesse o privilégio de realizar funções na corte, além de definir seu status. Alguns historiadores vêem osuji como uma projeção do próprio poder real.

Em inícios do século VI os possuidores dos mais altos kabane tinham criado uma estrutura capaz de vistoriar as mudanças dinásticas, possuindo um sistema rudimentar de administração fiscal. A distinção entre uji e kabane torna-se menos distinta à medida que este sistema difunde-se através das ordens 
inferiores da corte e nas aristocracias regionais. Por volta do século VIII o uso de nomes uji e kabane era comum entre os habitantes das vilas, sendo que os uji e kabane eram usualmente combinados e usados como títulos hereditários.

Com relação à situação externa, em meados do século VII, assistimos às tentativas expansionistas da China T'ang. Concentrando suas atenções preliminarmente nas fronteiras, enviava constantes expedições militares para o reino de Koguryo, ao norte da península coreana, preocupando a corte japonesa, pois este seria um passo para a conquista dos três reinos constituintes da península, permitindo a entrada de forças hostis no arquipélago japonês. De acordo com vários estudiosos, tanto a Reforma de Taika, quanto o Estado Ritsuryô, copiados do sistema administrativo chinês do período, estão intrinsecamente ligados à situação do continente, tendo sido introduzidos com o intuito de deixar o Japão em pé de igualdade com a China, possibilitando, deste modo, uma defesa eficiente.

A China T'ang consegue destruir Koguryo e unificar a península coreana sob seu domínio, fazendo com que o Imperador Tenchi (662-671) estabeleça postos militares em Tsushima, Iki e norte da costa japonesa de Kyûshû, caminho natural para uma eventual invasão do continente. A capital foi transferida para a moderna Ôtsu, às margens do lago Biwa, a uma distância segura do possível ataque das forças inimigas. Motivada pela situação externa e interna, a corte expande e racionaliza seu poder.

O Imperador Tenchi proclama uma nova e mais sistemática organização burocrática para o estado, morrendo, porém, antes de ter sua política totalmente implantada. Com sua morte, ocorrem rivalidades na sucessão, as quais são apontadas no prefácio.

Conforme alguns historiadores, o sucessor designado pela corte era Ôama mas, em vista da predileção do Imperador por Ôtomo, este abre-lhe caminho para a sucessão, provocando forte antipatia na corte e entre os uji que sempre valorizaram a linhagem, fazendo com que ficassem ao lado de Ôama.

Pouco antes da morte do Imperador, por razões táticas, Ôama renuncia ao mundo e se torna monge, refugiando-se no monte Yoshino. Seu irmão sucede ao trono, mas no mesmo ano irrompe a Revolta de Jinshin. Ôama vence, sendo coroado como Imperador Tenmu. Alguns autores vêem nesta situação a razão para que Tenmu ordenasse a reelaboração do Teiki, pois isto evitaria problemas futuros com relação à sucessão imperial.

O Estado Ritsuryô, formado em inícios do século VIII, tinha como principais características: administração centralizada, existência de representantes do Estado nas províncias (kokushi) e cargos de liderança hereditários. A classe aristocrata dominante mantinha-se através de taxas e impostos sobre a população campesina. As terras eram distribuídas entre os camponeses em iguais proporções per capita, podendo ser cultivada até a morte do arrendatário, após o que retornava ao governo.

A corte japonesa também adotou o suporte ideológico do sistema chinês. Isto torna-se evidente na análise do Jushichijô (Constituição dos Dezessete Arti- 
gos), atribuída a Shotoku Taishi e tratando dos princípios básicos para se criar um estado unificado. Estes princípios norteavam-se no Confucionismo, como podemos observar em seu décimo segundo artigo: " $O$ país não pode ter dois senhores, assim como as pessoas não podem ter dois mestres. $O$ imperador é o mestre de todas as pessoas".

O estabelecimento de um governo central pressupõe também a existência de uma capital permanente e a compilação de algum registro histórico nacional. No início do século VIII foi construída Nara, cópia da capital chinesa de C'hang-an. Nesta época, de acordo com Kato Shuichi, Nara foi a única cidade real do Japão, contando com uma população estimada em aproximadamente duzentos mil habitantes.

Esta cidide foi o centro operacional do Sistema Ritsuryô e, dez anos após seu estabelecimento, as duas histórias nacionais - o Kojiki (Relatos de Fatos Antigos) e o Nihonshoki (Crônicas do Japão), foram elaboradas. Ambas têm como ponto comum seu arranjo em ordem cronológica, podendo ser divididas em duas partes: uma lidando com as origens míticas e divinas da familia imperial e outra com o registro histórico dos feitos dos imperadores.

De acordo com Tsuda Sôkichi, nestes dois trabalhos vemos o empenho das forças do Sistema Ritsuryô tentando justificar sua posição. A seguir apresentamos o prefácio.

\section{Apresentação do Prefácio}

\section{Livro 1}

Prefácio

Conforme dito pelo vassalo Yasumaro':

No início a matéria primeva de todas as coisas do universo solidifica-se, mas ainda não surge nem princípio de vida e nem figura. Não há nome e nem movimento. Quem poderá conhecer a sua verdadeira forma'? Entretanto, quando os céus e a terra separam-se, surgem os três deuses ${ }^{3}$ que se tornam os pilares de toda a criação. As luzes e as trevas ${ }^{4}$ são separadas e os dois espíri-

1. Seu nome é Ôno-Assomi-Yasumaro, descendente de Kamuyaimimino Mikoto e fillho do Imperador Jinmu, foi designado em 711 para compilar a presente obra.

2. "Matéria primeva" reporta à concepçāo chinesa do taoísmo, atribuindo um estado inicial de inaniçāo, no qual, antes do surgimento do universo, os atributos da vida, traduzidos como "princípio de vida" e "figura", ainda nāo haviam surgido.

3. Os três deuses, ou seja, Amenominakanushino Kami, Takamimusuhino Kami e Kamumusuhino Kami, encontram-se mencionados no inicio do primeiro volume do Kojiki, sendo os primeiros a surgir no universo japonês. Deve-se notar que o nome musuhi significa literalmente "criaçāo" ou "vir à existência"

4. "Luzes e Trevas" baseiam-se no princípio chinês do Yin e Yang, de acordo com o qual todos os fenômenos nascem das oposiçóes destes dois elementos. Este principio surge a partir da dinastia chinesa de Han (202-220). 
$\operatorname{tos}^{5}$ tornam-se os genitores de todas as coisas existentes. Portanto, vai ao mundo dos vivos e ao mundo dos mortos ${ }^{6} \mathrm{e}$, retornando, ao purificar os olhos faz com que surjam os deuses do sol e da lua e, nos movimentos de imersão e emersão de seu corpo nas águas do mar, faz com que surjam inúmeros outros deuses. Através dos antigos ensinamentos, gera a terra e conhece o momento de criar as ilhas ${ }^{7}$. Apesar do princípio de todas as coisas estar num passado distante, podese conhecer o momento em que os deuses e as pessoas vieram à luz através dos primeiros sábios. $O$ espelho é pendurado ${ }^{8}$, as jóias expelidas ${ }^{9}$, cem imperadores sucedem-se ${ }^{10}$, a serpente é trucidada ${ }^{11}$, a espada colocada entre os dentes ${ }^{12}$ e a miríade de deuses ${ }^{13}$ surge à luz. Esta é a realidade conhecida. Além disso, os deuses pacificam o país após encontrarem-se no rio Yasu, purificando toda a terra ao altercarem-se na pequena praia ${ }^{14}$. A partir deste acontecimento, Hononinigino Mikoto desce pela primeira vez ao pico de Takachiho ${ }^{15}$ e o Imperador Kamuyamato ${ }^{16}$ visita a ilha de Akizu. Depara com um estranho urso ${ }^{17}$ que surge do rio, consegue a espada divina em Takakura e, quando os homens com cau$\mathrm{da}^{18}$ obstruem-lhe o caminho, enormes $\operatorname{corvos}^{19}$ conduzem-no até Yoshino ${ }^{20}$. Através de danças ${ }^{21}$, afugenta os inimigos e, através de cânticos, domina-os.

5. Mençāo ao deus masculino Izanakino Mikoto e à deusa feminina Izanamino Mikoto, tidos como genitores de todos os seres animados e inanimados.

6. Izanami, mencionada na nota 5 , após conceber o fogo, cria neste ato a morte, dando início ao Neno Kuni ("País dos Mortos"). Izanaki a persegue sem sucesso e, ao retornar ao mundo dos vivos, através dos rituais de purificaçāo, cria os deuses Amaterasuômi Kami, Tsukyomino Mikoto e Takekaya Susanoono Mikoto.

7. Vide nota 5.

8. Alusāo ao episódio em que houve provocaçōes de Susanoo à deusa Amaterasu. Esta se fecha na caverna de Takamagahara, mergulhando o mundo em trevas. Amaterasu, impelida pela curiosidade frente à movimentaçāo dos deuses que dançavam e enfeitavam o espaço com espelhos e jóias, reaparece proporcionando novamente as luzes ao mundo japonês.

9. Episódio referente à contenda entre Susanoo e Amaterasu, em que esta prova a fidelidade das intençōes deste.

10. "Cem imperadores" indica, em seu sentido original, uma linhagem eterna de monarcas.

11. Referência a Susanoo que, após ter sido banido para Izumo, lá consegue derrotar a terrivel serpente de oito cabeças, Yamatano Orochi, salvando Kushiinadahime, que estava prestes para ser devorada. Eles se casam e passam a habitar em Suga.

12. Vide nota 9.

13. O sentido original indica uma linha sucessiva de descendentes dos deuses.

14. Referência ao clímax da mitologia contida na obra Kojika, ou seja, à cessaao das terras dos descendentes de Susanoo aos descendentes de Amaterasu.

15. Vulcāo onde, de acordo com a kenda, Hononinigino Mikoto pisou quando desceu à terra.

16. Referência ao lendário Imperador Jinmu (?), considerado o primeiro imperador e fundador da dinastia atual.

17. Provavelmente trata-se dos deuses de Kumano (atual regiāo da prefeitura de Wakayama), que apareceramlhe sob a forma de urso.

18. De acordo com uma das explicagóes de Nobuhiro Matsumoto, em Nihon no Shinwa (Mitologia Japonesa), os japoneses acreditavam que os habitantes das montanhas assemelhavam-se a animais.

19. Provavelmente sāo os pássaros sagrados mensageiros da deusa Amaterasu que lhe serviram como guias, conforme Jun Tsugita, Kojiki Shinkó (Nova Interpretaçäo do Kojika)

20. Regiāo montanhosa nas proximidades da atual Nara, referida em inúmeros poemas da antiguidade devido à sua beleza.

21. Referência aos guerreiros do Imperador Jinmu, que venceram os "homens com caudas" na conquista das terras do pais. 
Então, é iluminado em sonhos ${ }^{22}$ e passa a reverenciar os deuses do céu e da terra. Por esta razão, a partir deste momento, passa a ser conhecido como o Imperador Sábio. Em seguida, ao contemplar a fumaça ${ }^{23}$, sente pena de todo o povo. Por isto, ainda hoje é cognominado de o Imperador Virtuoso. Então, as fronteiras são fixadas e a nação conhece a prosperidade durante o reinado de Chikatsuômi ${ }^{24} \mathrm{e}$, durante o reinado de Tohotsuasuka ${ }^{25}$, os títulos de kabane são corrigidos $^{26} \mathrm{e}$ os clãs devidamente escolhidos. Cada reinado difere em avanço ou em estagnação, em esplendor ou em simplicidade, e, refletindo-se bem acerca do passado, estes fatos servem de modelo para se superar as falhas do presente. Chega a era do Imperador que assume Ohoyashima do palácio de Kyomihara em Asuka ${ }^{27}$. Este já portava em si as qualidades reais de um monarca, latentes no caráter de dragão e nos clamores incessantes dos trovões ${ }^{28}$. Em sonhos, ele preconiza através de cânticos que deverá dar continuidade aos trabalhos divinos e, ao atravessar o rio da noite ${ }^{29}$, é revelado-lhe que sucederá ao trono. Entretanto, como ainda não é chegada a hora de seu destino realizar-se ${ }^{30}$, retira-se às montanhas do sul $\mathrm{e}$, à medida que os que lhe são simpáticos crescem em número, avança como um tigre pelas províncias do leste. A comitiva do príncipe parte apressadamente, atravessando rios e montanhas. Os seis regimentos brandem como trovões e os três exércitos avançam como relâmpagos. Revela-se a força das armas e bravos guerreiros juntam-se como fumaças. Estandartes vermelhos realçam os guerreiros e as forças inimigas são vencidas, quebrando-se como telhas. Num curto espaço de tempo, purifica-se naturalmente e por completo a fatídica atmosfera. Então os animais de luta são libertados, folgam-se os cavalos e, com humildade, ele retorna à capital, quando as bandeiras são enroladas e as armas recolhidas e, em meio a manifestações de júbilo, lá se estabelece. No terceiro miês do ano em que Marte se aproxima das Plêiades ${ }^{31}$, ascende ao trono no

22. Referência ao Imperador Sujin (?) construtor de um templo dedicado à Amaterasu, em Kasanui, onde depositou dois dos três tesouros sagrados - a espada e o espelho.

23. Referência ao episódio do Imperador Nintoku (?) que, observando as casas da populaçāo sem fumaça, associa o fato à falta de comida, diminuindo-lhes os impostos.

24. Referência ao Imperador Seimu (?), que fixou os limites das provincias (kauni) e dos distritos (agaıa).

25. Referência ao Imperador Ingyô (?). Durante seu reinado, houve reformas nos registros de nomes e titulaçōes.

26. De acordo com Yamada Yoshio, a reverência aos deuses, leis benevolentes, designaçāo das fronteiras e correçāo dos nomes e titulaçōes eram considerados os princípios básicos de um bom governo na antiguidade japonesa.

27. Referência ao episódio em que o Imperador Tenmu (673-686), vence o Imperador Kôbun na Revolta de Jinshin, em 672, em jogo de disputas na sucessāo imperial.

28. "Caráter de dragāo" (literalmente "dragāo que ainda nāo subiu aos céus") é uma expressāo de origem chinesa que atribui ao príncipe as qualidades de um monarca, antes mesmo de ascender ao trono; $e$ "clamores dos trovóes" simboliza os sinais do convite ao trono.

29. Por ocasiāo da Revolta de Jinshin, o futuro Imperador Tenmu, ao atravessar o rio Yoko, em Nabari (atual prefeitura de Mie), previu a sua ascensāo ao trono pelas nuvens escuras.

30. Provavelmente por razóes táticas, Tenmu renuncia ao mundo, refugiando-se no monte Yoshino, antes da morte do Imperador Tenchi.

31. Ano de 673. Desde 604 o Japāo adotara o calendário chinês, o qual perdurou até 1872. 
palácio de Kyomihara. Seu governo ultrapassa o de Kenkô $\hat{0}^{32}$ e sua virtude excede à do Imperador de $S_{h u} \hat{u}^{33}$. Ele recebe os três símbolos da realeza ${ }^{34}$, passando a reinar nas seis direções ${ }^{35} \mathrm{e}$, após a sua ascensão ao trono imperial, unifica os oito cantos ${ }^{36}$. Seu reinado ocorre em conformidade com os dois movimentos ${ }^{37} \mathrm{e}$ na harmonia dos cinco elementos ${ }^{38}$. Estabelece os caminhos dos deuse ${ }^{39}$, incentiva os bons costumes e, realizando tudo com nobreza de caráter, governá sobre toda a extensão do país. Mas seus feitos vão muito mais além - a sua sabedoria era mais vasta que os oceanos; estuda exaustivamente as eras antigas e, seu espírito, reluzente como um espelho, vislumbra claramente os feitos dos seus ancestrais $^{40}$. Assim, o Imperador ordena o seguinte:

Chegou ao meu conhecimento que o Teiki41 e o Honjit2 em poder das famílias aristocratas já estão distantes da verdade, tendo sido nestes introduzidos muitos enganos. Por isso, devemos consertar estes erros ainda em nossos dias pois, com o decorrer dos anos, a sua verdadeira essência corromper-se-á por completo. É desnecessário dizer que estas são as linhas mestras da organização do país e as diretrizes do poder imperial. Com isto, procurar-se-á compilar o Teiki e consertar os erros contidos no Kyâjji eliminando-os e estabelecendo a verdade, a fim de perpetuá-los às ge raçōes vindouras.

Nesta ocasião havia um toneri ${ }^{43}$ do clã Hieda, cujo nome era Are, contando já com a idade de 28 anos. Ele era de grande perspicácia e sabedoria e, o que quer que seus olhos vissem, mesmo que apenas uma vez, conseguia reter tudo na memória e, o que quer que porventura escutasse, mesmo que apenas uma visz, conseguia reter tudo em seu espírito. É ordenado-lhe, então, que aprenda e guarde na memória o Tennôno Hitsugit4 e o Sendaino Kyûji ${ }^{45}$ desde as eras anti-

32. Ou seja, o lendário Imperador chinês Hoang-gti, um dos cinco imperadores lendários da antiguidade chinesa, que iria de $2852-2205$ a.C.

33. Ou seja, o Imperador chinês Bunô da dinastia chinesa Tcheou (1122-221 a.C.). Esta dinastia foi a mais longa da história chinesa.

34. Ou seja, as jóias (peças de adorno em forma de meia-lua), o espelho e a espada, os três símbolos do poder imperial japonês.

35. Refere-se aos quatro pontos cardeais, acrescidos do céu e da terra, abarcando toda a extensāo do Japão.

36. Indica todas as direçōes, isto é, a totalidade do universo.

37. Ou seja, o Yin e o Yang. Vide nota 4.

38. Os cinco elementos sảo a água, o fogo, a madeira, o metal e a terra. Na filosofia chinesa antiga o universo com todos os seus fenômenos era comandado por estes cinco elementos.

39. As seguintes linhas nortearam a política educacional e religiosa do Imperador Tenmu: ressurgimento do serviço religioso xintoista, compilaçāo de leis e ordenanças, determinaçāo dos limites das províncias, estabelecimento de regras para comportamento e cerimônias da corte etc.

40. Tem-se aqui uma alusāo ao seu trabalho de compilaçāo histórica.

41. Literalmente Crônicas Imperiais, trata-se de um documento contendo registro genealógico da família imperial, além de outros dados e lendas concernentes aos imperadores.

42. Literalmente Fatos Antigos, sāo documentos registrando mitos, lendas, cançōes, tradiçōes orais em poder dos clās.

43. Servo de imperadores ou príncipes. Geralmente eram homens e mulheres que descendiam de familias de renome.

44. Mesmo que Teiki, vide nota 40.

45. Mesmo que Kyúji, vide nota 41. 
gas. Entretanto, o tempo passa e o mundo se transforma $a^{46}$, não conseguindo completar o seu trabalho. Tudo o que respeitosamente sei é que a sua alteza imperial ${ }^{47}$, quando se torna princesa, enche-se de luz, conhecendo os três universos $^{48}$. Mesmo governando no pavilhão púrpura ${ }^{49}$, sua virtude estende-se até os confins aonde os cavalos podem alcançar com seus cascos e, mesmo sentada em seu trono, a Imperatriz ilumina até os limites da amplidão dos mares aonde os navios podem atingir. Sua luz é contínua como o brilho do sol e as nuvens de bom agouro se expandem como fumaça. Os escribas ${ }^{50}$ incessantemente registram os sinais dos galhos de diferentes árvores enlaçando-se, das espigas brotando ein abundância de uma única haste, dos fogos erguidos proclamando a chegada dos inúmeros tributários, de suas palavras incessantemente traduzidas, não havendo mês em que os depósitos da corte fiquem vazios. Seu nome elevase acima do de Bunmei ${ }^{\text {s1 }}$ e sua virtude é certamente superior até mesmo à de Ten'itsu ${ }^{52}$. Assim, lamentando-se pelas deturpações e erros do Kyâjii, sua alteza ordena que estes erros mesclados no $S_{e n k i}{ }^{53}$ sejam corrigidos e, no décimo oitavo dia do nono mês do quarto ano de Wado ${ }^{54}$, é a mim, Ôno-Yasumaro, assim determinado: "Que se registre e apresente à Imperatriz o Kyâji que foi ordenado a Hiedano Are memorizar", e, reverentemente, de acordo com o ofício imperial, eu recolho tudo minuciosamente. Entretanto, por ser uma época antiga e distante no passado, quando todas as palavras e seus significados eram simples, torna-se uma tarefa árdua a transposição em ideogramas chineses das suas frases e sentenças. Logo percebi, entretanto, que se tudo fosse escrito no estilo japonês as palavras não coincidiriam com seu significado e, se tudo fosse escrito no estilo chinês ${ }^{55}$, os fatos tornariam-se deveras longos. Por este motivo, aqui, em alguns casos, dentro da mesma sentença, utilizo indiscriminadamente as palavras tomadas nos dois estilos e, além disso, dependendo das circunstâncias, registro tudo de acordo com o estilo japonês. Para deixar claro o significado das palavras de difícil entendimento, utilizo glosas explicativas e deixo totalmente sem observações aquelas cuja interpretação considero fácil. Além disso, com relação aos nomes dos clãs, o clã Nichige, por exemplo, foi registrado como Kusaka e os nomes próprios, como os grafados em Tai, foram registrados como Tarashi. As letras às quais já existe certa familiaridade, são deixadas de acordo

46. Referência à morte do Imperador Tenmu, que ocorre um ano após ter ordenado a Hiedano Are a elaboraçāo dos registros históricos.

47. Referências às virtudes da Imperatriz Genmei (708-714).

48. Equivale ao céu, à terra e às pessoas.

49 Nome de um recinto do palácio imperial.

50. Espécie de funcionários públicos encarregados da compilaçāo de registros históricos.

51. Legendário imperador chinês, fundador da dinastia Hsia, em 2205 a.C.

52. Fundador da primeira dinastia chinesa de Shang (1766-122 a.C.) com dados históricos comprovados.

53. O mesmo que Teiki, vide nota 40.

54. 711 d.C.

55. Estilo chinês, literalmente "leitura pelo som", é a utilizaçåo do ideograma chinês com o aproveitamento apenas de seu caráter fonético. Estilo japonês, literalmente "leitura pelo significado", é a utilizaçāo do ideograma chinês no seu aspecto semântico. 
com a sua forma original, sem alterações. Tudo o que está narrado começa a partir da criação dos céus e da terra, estendendo-se até a época do reinado de Oharida $^{56}$. Deste modo, o primeiro volume registra desde Ameno Minakanushino $\mathrm{Kami}^{\text {'7 }}$, até Hikonagisatakeugayafukiaezuno Mikoto ${ }^{58}$; o segundo volume registra desde o Imperador Kamuyamatoiwarebiko ${ }^{59}$ até o reinado de $\mathrm{Homuda}^{60}$ e o terceiro volume registra desde o Imperador Ohosazaki ${ }^{61}$ até o reinado no palácio de Ôharida. Este é o conteúdo dos três volumes que aqui respeitosamente apresento. Assim eu, Yasumaro, declaro com toda a reverência e respeito.

Décimo oitavo dia do primeiro mês do quinto ano de Wado ${ }^{62}$.

Ônoasomi Yasumaro, quinta ordem do mérito, quinto posto superior ${ }^{63}$.

\section{Consideraçōes Acerca do Prefácio}

De modo geral, podemos dividir a narrativa do prefácio em três partes:

1. Narrativa da criação do universo japonês ao reinado do Imperador Tenmu.

2. Narrativa do processo de compilação da obra.

3. Narrativa focalizando o ano de 711, durante o reinado da Imperatriz Genmei, e discussão acerca do modo de compilação propriamente dito.

$O$ prefácio apresenta apenas as condições da compilação, as pessoas envolvidas e as circunstâncias do processo, não havendo discussões com respeito ao seu conteúdo.

Já no decorrer da primeira parte do prefácio, o autor apresenta simbolicamente os empecilhos com que a classe dominante se defrontou no próprio processo de legitimação de sua linhagem e de seu poder político, através de uma amostragem dos principais fatos narrados no Kojiki.

Embora a exata proveniência do material não possa ser determinada, a julgar pela rapidez com que o trabalho foi completado, uma vez que o ofício imperial foi editado no décimo oitavo dia do nono mês do quarto ano de Wado e Yasumaro terminou a compilação no décimo oitavo dia do primeiro mês do quinto ano de Wado, num período de tempo de aproximadamente quatro meses, muitos estudiosos sugerem que ele tinha em mãos um documento único,

56. Imperatriz Suiko (593-628), incentivadora da implantaçāo do budismo no Japāo.

57. Deus que, antes da criaçāo, permanecia imóvel no centro do mundo. Izanami e Izanaki sāo seus descendentes (vide nota 5 ).

58. Pai do Imperador Jinmu.

59. Imperador Jinmu, primeiro imperador do Japāo, de acordo com a lenda.

60. Imperador Ôjin (?).

61. Imperador Nintoku (?).

62. Corresponde ao dia 28 de janeiro de 711.

63. O "quinto posto superior" era concedido àqueles que tinham se distinguido em serviços militares. Segundo consta, o feito de Yasumaro está relacionado com a Revolta de Jinshin. 
provavelmente composto anteriormente a partir de várias fontes orais e escritas correntes na família imperial, nas várias famílias nobres e entre o povo.

Uma leitura ainda que superficial do prefácio revela estar este intrinsecamente relacionado à Revolta de Jinshin e às transformações político-sociais em curso durante o período. De acordo com o prefácio, o Imperador Tenmu planeja a compilação e retificação dos registros indicados como Teiki e Kyûji, em posse dos uji, logo após esta revolta, devido a estes já estarem longe da verdade.

De acordo com vários estudiosos, a origem da compilação relaciona-se com prováveis distúrbios na relação senhor-servo e na formação das famílias tradicionais. Tôma Seita, por exemplo, acredita que a Reforma de Taika, de 645, modificou a estrutura do sistema uji-kabane, unidade de grupo primária e base da propriedade privada de terra. Além disso, como a posição e a função na corte e o grau de relação com a família imperial eram determinados em função da ancestralidade, tornava-se imprescindivel o estabelecimento de um sistema definido e definitivo de títulos baseados em registros genealógicos corretos e aceitáveis pela corte e pela familia imperial. Com isso torna-se clara a importância da compilação com relação à própria sustentação ideológica da camada dominante.

Os registros genealógicos e históricos também seriam imprescindíveis para o término da reorganização administrativa iniciada com a Reforma de Taika e concluída no reinado da Imperatriz Genmei, pois dariam forma legal a estas reformas.

\section{Bibliografia}

ABE, Hiroko. "Genmei Tennôto Kojikino Tanjô" ("A Imperatriz Genmei e o Nascimento do Kojiki"), Nihon Bungaku Kenkyû Shiryô - Kojiki, Nihonshoki, (Materiais de Pesquisa sobre a Literatura Japonesa - Kojiki e Nihonshoki), Tóquio, Yaseidô, 1970, vol. 2.

Hisamatsu, Sen'ichi. Nihon Bungakushi - Jôdai (História da Literatura Japonesa - Antiguidade), Tóquio, Shibundô, 1977.

KATo, Shuichi. Nihon Bungakushi Josetsu (Introdução à História da Literatura Japonesa), Tóquio, Chikuma Shobô, 1988.

_. "Kojiki", Nihon Koten Bungaku Zenshû (Obras Completas da Literatura Japonesa Clás. sica), Tóquio, Shôgakkan, 1971.

- "Kojiki", Shinchô Nihon Koten Shûsei (Nova Antologia da Literatura Japonesa Clássica), Tóquio, Shinchôsha, 1979.

MATSUMOTo, Nobuhiko. Nihonno Shinwa (Mitologia Japonesa), Tóquio.

Mrtani, Eiichi. "Kojikino Seiritsu - Jobunno Kaishaku wo Megutte" ("A Formação do Kojiki Em Foco a Interpretação do Prefácio"), Nihon Bungaku Kenkyû Shiryô - Kojiki, Nihonshoki, (Materiais de Pesquisa sobre a Literatura Japonesa - Kojiki e Nihonshoki), Tóquio, Yûseidô, 1970, vol. 1.

NisHimIYA, Kazutani. "Kojiki Jobunno Seiritsunitsuite" ("Consideraçōes acerca do Prefácio do Kojiki"), Nihon Bungaku Kenkyû Shiryô - Kojiki, Nihonshoki, (Materiais de Pesquisa sobre a Literatura Japonesa - Kojiki e Nihonshoki), Tóquio, Yâseidô, 1970, vol. 1.

TsudA, Sôkichi. Nihon Jôdaishino Kenkyû (Estudos sobre a História Japonesa da Antiguidade), Tóquio, Iwanami Shoten, 1947.

Tsugrta, Jun. Kojiki Shinkô (Nova Interpretação do Kojiki), Tóquio. 